\title{
Effectivity of Esomeprazole Compared with Lansoprazole in the Treatment of Pediatric with Gastritis
}

\author{
Fini Kollins ${ }^{1}$, Supriatmo Supriatmo ${ }^{1 *}$, Rina Saragih ${ }^{1}$ (D), Ilhamd Ilhamd ${ }^{2}$ \\ ${ }^{1}$ Department of Pediatric, Faculty of Medicine, Universitas Sumatera Utara, Medan, Indonesia; ${ }^{2}$ Department of Internal \\ Medicine, Faculty of Medicine, Universitas Sumatera Utara, Medan, Indonesia
}

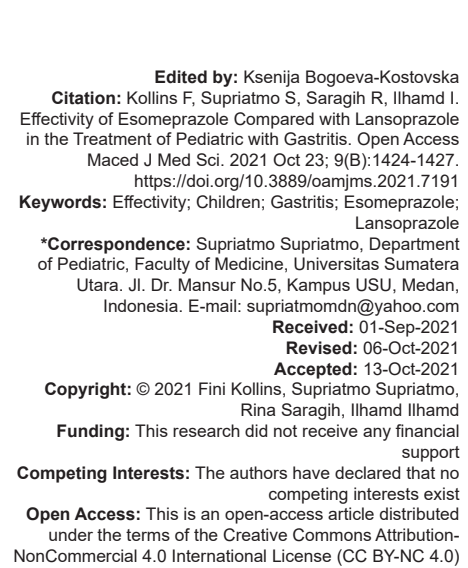

Introduction

Gastritis is a common medical problem that is frequently underestimated can be a troublesome disease for children. The overall incidence of gastritis in pediatric is still not determined. A Canadian study showed approximately 1 of 2500 pediatrics were admitted to hospital diagnosed with gastritis [1] The imbalance of aggressive factors and mucosal defensive is the cause of gastric mucosa inflammation. Abdominal pain is a common symptom of gastritis due to mucosal ulceration. Knowledge of gastritis and mucosal ulceration are very important for the treatment of abdominal pain in pediatric [2].

Usage of proton pump inhibitor (PPI) for pediatrics has been increased dramatically. Studies showed that PPIs prescriptions from 1999 to 2000 for pediatric $<12$ months have increased 7.5 folds [3]. PPIs have superiority effect by inhibit terminal pathway of gastric acid secretion and can be given once daily for most cases. Effectiveness of PPIs treatment requires knowledge of the mechanism gastric acid production, requirement of $\mathrm{PPIs}$ activation to bind the proton pump and the reason of inactivation, also pharmacokinetics and pharmacodynamics of PPIs [4].

A clinical trial showed superiority of esomeprazole compared to lansoprazole for adults patiens, but limited for pediatric cases [5]. This study focused to compare effectivity of Esomeprazole with lansoprazole for healing the symptoms of gastritis in pediatric patients.

\section{Methods}

A randomized and single-blind (assessors) controlled trial was done at $\mathrm{H}$. Adam Malik General hospital at Medan. This research followed the International Convention on Harmonization of Good Clinical Trial Practice (ICH-GCP) and was approved by Health Research Ethical Committee Medical Faculty of Universitas Sumatera Utara/RSUP H. Adam Malik(under the ethics no: 145/KEP/USU/2020). All parents provided and approved informed consent and then randomization scheme with computer generated. 


\section{Patients}

Boy and girl children aged 2-18 year with symptoms that is abdominal pain, nausea, vomiting, haematemesis, or bloody stool and confirmed gastritis from gastroscopy. Patients with history of PPIs, H2 blockers, non steroid anti-inflammatory drugs (NSAIDs), dexamethasone usage within 14 days, any conditions that can affect gaster mucosa, and any digestive surgeries were excluded. Forty-eight patients were needed with 24 patients for each group for minimal samples.

\section{Study procedures}

Patients that complied with to study's criteria and agreed to sign informed consent were collected information about the symptoms. After confirmation diagnosis of Gastritis by gastroscopy, then the patients randomized into two groups of treatment, the lansoprazole treatment group (15 $\mathrm{mg}$ if $<30 \mathrm{~kg}$ and $30 \mathrm{mg}$ if $>30 \mathrm{~kg}$ ) and esomeprazole treatment group (0,4-0,8 mg per kg body weight). Medication for both groups will be given orally for 14 days. After treatment, all the subjects were re-evaluated from initial symptoms. $\mathrm{P}$-value of this study was calculated with the $\chi^{2}$ test.

\section{Results}

From total of 57 patients that fit the requirement and gastroscopy examination confirmed gastritis were 54 patients and all enrolled in this study; 27 patients received lansoprazole, and 27 patients received esomeprazole with 2 patients drop out. Two treatment groups have similar baseline characteristics and demographics (Table 1).

Table 1: Baseline characteristics and demographic of patients evaluable for gastritis

\begin{tabular}{lll}
\hline & Esomeprazole group $(\mathrm{n}=25)$ & Lansoprazole group $(\mathrm{n}=27)$ \\
\hline Gender & & \\
Male & 9 & 8 \\
Female & 16 & 19 \\
Age (year) & $13.4(5.1)$ & $13.1(5.3)$ \\
Weight $(\mathrm{kg})$ & $67.2(18.6)$ & $67.5(18.2)$ \\
Height $(\mathrm{cm})$ & $141.1(15.7)$ & $139.8(15.9)$ \\
Nutritional status & & \\
$\quad$ Overweight & 7 & 10 \\
$\quad$ Good & 11 & 9 \\
$\quad$ Underweight & 7 & 8 \\
$\quad$ Malnutrition & 0 & 0 \\
Family history & & \\
$\quad$ With Gastritis & 19 & 23 \\
$\quad$ Without Gastritis & 6 & 4 \\
Clinical symptoms & & \\
Abdominal pain & 12 & 17 \\
Vomiting & 5 & 5 \\
Haematemesis & 5 & 5 \\
Nausea & 3 & 0 \\
Black and tarry stool & 0 & 0 \\
\hline
\end{tabular}

\section{Effectivity}

Lansoprazole group after 14 days treatment showed that 5 patients $(18.5 \%)$ from 27 patients compared to esomeprazole group showed that 8 patients $(32 \%)$ from 25 patients still have persistent initial symptoms (Table 2). Chi-square analysis using a computer program showed no significance between the two groups $(p=0.262)$.

Table 2: Comparison effectiveness between esomeprazole and lansoprazole

\begin{tabular}{llll}
\hline Treatment & \multicolumn{2}{l}{ Symptoms after treatment } & $\mathrm{p}$ \\
\cline { 2 - 3 } & Yes $(\%)$ & No $(\%)$ & $0.262^{\mathrm{a}}$ \\
\hline Lansoprazole & $5(18.5)$ & $22(81.5)$ & \\
Esomeprazole & $8(32)$ & $17(68)$ & 39 \\
Total & 13 & 39 & \\
\hline aPearson chi-square & &
\end{tabular}

From Table 3, lansoprazole and esomeprazole administration for 14 days have same effectivity in treating gastritis symptoms except abdominal pain. Lansoprazole groups has $88.24 \%$ free of abdominal pain compared to esomeprazole group for only $66.67 \%$ free of abdominal pain.

Table 3: Effectiveness of esomeprazole and lansoprazole for each symptom

\begin{tabular}{llllll}
\hline Symptoms & Lansoprazole & & & \\
\cline { 2 - 3 } & Persistent $(\%)$ & Recovery $(\%)$ & & Persisten (\%) & Recovery (\%) \\
\hline Abdominal pain & $2(11.76)$ & $15(88.24)$ & & $4(33.33)$ & $8(66.67)$ \\
Vomiting & $1(20)$ & $4(80)$ & & $1(20)$ & $4(80)$ \\
Haematemesis & $2(40)$ & $3(60)$ & $2(40)$ & $3(60)$ \\
Nausea & - & - & $1(33.33)$ & $2(66.67)$ \\
\hline
\end{tabular}

\section{Discussion}

Gastritis is known as damage of gastric mucosa due to inflammatory reactions. Imbalance of defensive dan aggressive factors cause complex multifactor pathologic process, and this process depends on individual's cellular and humoral response. This study showed that the incidence of gastritis between females and males is $67.3 \%$ and $32.7 \%$ or $2: 1$. Studies showed that gastritis incidence in pediatric between female and male were quite similar [6], [7].

Based on age, the incidence of gastritis in this study was dominated by $13-15.9$ years group patients that is 24 patients $(46.1 \%)$. The median age of patients with gastritis in this study was 13.5 years with ranging from 2.6 year to 17.7 year. Epidemiology studies also showed a similar result. A study from Japan showed the mean age of gastritis incidence in pediatric was $11.3 \pm 3.4$ years for non-nodular gastritis and $12.7 \pm 2.7$ years for nodular gastritis [6]. Other study showed that age between 11 and 12 years has gastritis incidence till 63\% [8].

This study showed that incidence of gastritis is most commonly from a family with a history of gastritis. Incidence of gastritis from family with history of gastritis were 42 children or $80.8 \%$ compared with 10 children or $19.2 \%$ without family history of gastritis. Other study showed that family with history of gastritis caused mainly by Helicobacter pylori as major predisposition 
factors. This proved that history taking of family history is one of the improtant informations to be asked during the examination [8].

Clinical symptoms from this study were dominated by abdominal pain $(55.8 \%)$ followed by vomiting and hematemesis (respectively 19.2\%). Research by Boukthir et al. to study prevalence and characteristics of pediatric chronic gastritis showed that the most common symptom is recurrent abdominal pain $(67.4 \%)$ followed by vomiting $(19.5 \%)$ and upper gastrointestinal bleeding (18.6\%) [9]. Research by Kato et al. also showed that the most common symptom of pediatric gastritis in Japan was also abdominal pain followed by vomiting [6].

There is a study showed that obesity in children have higher chance to suffer gastroesophageal reflux disease (GERD) [10]. The only studies of PPI pharmacokinetics in obesity children were pantoprazole. Suggestion of those studies were used lean-bodyweight-based (LBW) than total body weight (TBW) in calculate dosage of pantoprazole because obese children need lower doses [11], [12]. Long-term usage of PPI decreased uptake of micronutrients that need low $\mathrm{pH}$ such as vitamin B12, vitamin $\mathrm{C}$, iron, calcium, magnesium, zinc, and $\beta$-carotene [13].

There is not any yet comparison study of effectivity between esomeprazole and lansoprazole in pediatric, however in adult patients still a controversy. A study by Fennerty et al. and Castell et al. that compared esomeprazole with lansoprazole in adult patients with moderate to severe erosive esophagitis showed that esomeprazole significantly more effective in time to healing and symptoms resolved [14], [15]. However, multicenter research by Chey et al. that compared esomeprazole $40 \mathrm{mg}$ with lansoprazole $30 \mathrm{mg}$ for gastro-esofagela reflux disease (GERD) showed no significant difference between two groups in resolving the symptoms [16]. Similar to this study's result that showed no significant difference between the two groups treatment $(p=0.262)$.

This study showed lansoprazole and esomeprazole were effective for gastritis tretament. Similar to study by Faure et al. with cure rate $80 \%$ for 23 pediatric patients with refluks esophagitis that treated lansoprazole for 14 days and only 3 patients have side effect [17]. Multicenter dan randomized clinical trial by Gilger et al. showed that esomeprazole treatment for pediatric patients has effectivity almost $91.4 \%$ with side effect rate only $9.3 \%$ [18].

\section{Conclusion}

This study showed no significant difference between lansoprazole and esomeprazole treatment for pediatric with gastritis in terms of healing time and symptoms resolved. However, further randomized clinical trial and multicenter studies are suggested.

\section{References}

1. Drumm B, Rhoads JM, Stringer DA, Sherman PM, Ellis LE, Durie PR. Peptic ulcer disease in children: Etiology, clinical findings, and clinical course. Pediatrics. 1988;82(3):410-4. PMid:3405676

2. Blecker U, Mehta DI, Gold BD. Pediatric gastritis and peptic ulcer disease. Indian J Pediatr. 1999;66(5):725-33. https://doi. org/10.1007/BF02726263

\section{PMid:10798134}

3. Barron JJ, Tan H, Spalding J, Bakst AW, Singer J. Proton pump inhibitor utilization patterns in infants. $\mathrm{J}$ Pediatr Gastroenterol Nutr. 2007;45(4):421-7. https://doi.org/10.1097/ MPG.0b013e31812e0149

PMid:18030207

4. Ward RM, Kearns GL. Proton pump inhibitors in pediatrics: Mechanism of action, pharmacokinetics, pharmacogenetics, and pharmacodynamics. Pediatr Drugs. 2013;15(2):119-31. https://doi.org/10.1007/s40272-013-0012-x

PMid:23512128

5. Miner P Jr., Katz PO, Chen Y, Sostek M. Gastric acid control with esomeprazole, lansoprazole, omeprazole, pantoprazole, and rabeprazole: A five-way crossover study. Am J Gastroenterol. 2003;98(12):2616-20.

PMid:14687806

6. Kato S, Nishino Y, Ozawa K, Konno M, Maisawa S, Toyoda S, et al. The prevalence of Helicobacter pylori in Japanese children with gastritis or peptic ulcer disease. J Gastroenterol. 2004;39(8):734-8. https://doi.org/10.1007/s00535-004-1381-2 PMid:15338366

7. Sierra D, Wood M, Kolli S, Felipez LM. Pediatric gastritis, gastropathy, and peptic ulcer disease. Pediatr Rev. 2018;39(11):542-9. https://doi.org/10.1542/pir.2017-0234 PMid:30385583

8. Ertem D, Harmanci H, Pehlivanoğlu E. Helicobacter pylori infection in Turkish preschool and school children: Role of socioeconomic factors and breast feeding. Turk J Pediatr. 2003;45(2):114-22

PMid:12921297

9. Boukthir S, Aouididi F, Mazigh Mrad S, Fetni I, Bouyahya O, Gharsallah L, et al. Chronic gastritis in children. Tunis Med. 2007;85(9):756-60.

PMid:18254306

10. Koebnick C, Getahun D, Smith N, Porter AH, Der-Sarkissian JK, Jacobsen SJ. Extreme childhood obesity is associated with increased risk for gastroesophageal reflux disease in a large population-based study. Int J Pediatr Obes. 2011;6(2):e257-63. https://doi.org/10.3109/17477166.2010.491118. PMid:20615162

11. Shakhnovich V, Smith PB, Guptill JT, Zhao J, Kearns GL. Obese children require lower doses of pantoprazole than nonobese peers to achieve equal systemic drug exposures. J Pediatr. 2018;193:102-8.e1. https://doi.org/10.1016/j.jpeds.2017.10.011 PMid:29389444

12. Shakhnovich V, Abdel-Rahman S, Friesen CA, Weigel J, Pearce RE, Gaedigk A, et al. Lean body weight dosing avoids excessive systemic exposure to proton pump inhibitors for children with obesity. Pediatr Obes. 2019;14(1):1-4. https://doi. 
org/10.1111/ijpo.12459

PMid:30257076

13. Mohn ES, Kern HJ, Saltzman, Mitmesser SH, McKay DL. Evidence of drug-nutrient interacctions with chronic use of commonly prescribed medications: An update. Pharmaceutics. 2018;10(1):36. https://doi.org/10.3390/pharmaceutics10010036 PMid:29558445

14. Fennerty $\mathrm{MB}$, Johanson JF, Hwang $C$, Sostek $M$. Efficacy of esomeprazole $40 \mathrm{mg}$ vs. lansoprazole $30 \mathrm{mg}$ for healing moderate to severe erosive oesophagitis. Aliment Pharmacol Ther. 2005;21(4):455-63. https://doi. org/10.1111/j.1365-2036.2005.02339.x

PMid:15709997

15. Castell DO, Kahrilas PJ, Richter JE, Vakil NB, Johnson DA, Zuckerman S, et al. Esomeprazole $(40 \mathrm{mg})$ compared with lansoprazole $(30 \mathrm{mg})$ in the treatment of erosive esophagitis. Am J Gastroenterol. 2002;97(3):575-83. https://doi. org/10.1111/j.1572-0241.2002.05532.x
PMid:11922549

16. Chey W, Huang B, Jackson RL. Lansoprazole and esomeprazole in symptomatic GERD: A double-blind, randomised, multicentre trial in 3000 patients confirms comparable symptom relief. Clin Drug Investig. 2003;23(2):69-84. https://doi. org/10.2165/00044011-200323020-00001

17. Faure C, Michaud L, Khan Shaghaghi E, Popon M, Laurence M, Mougenot JF, et al. Lansoprazole in children: Pharmacokinetics and efficacy in reflux oesophagitis. Aliment Pharmacol Ther. 2001;15(9):1397-402. https://doi. org/10.1046/j.1365-2036.2001.01076.x

PMid:11552911

18. Gilger MA, Tolia V, Vandenplas Y, Youssef NN, Traxler B, Illueca M. Safety and tolerability of esomeprazole in children with gastroesophageal reflux disease. J Pediatr Gastroenterol Nutr. 2008;46(5):524-33. https://doi.org/10.1097/ MPG.0b013e318176b2cb

PMid:18493207 